\title{
Nd:YAG lazer kaynağı ile birleştirilen Ti6A14V alaşımının mikroyapı ve mekanik özelliklerine 1sıl işlemlerin etkileri
}

\author{
Ceyhun KÖSE ${ }^{1, *}$, Engin KARACA ${ }^{2}$ \\ ${ }^{1}$ Tokat Gaziosmanpaşa Üniversitesi, Mühendislik ve Doğa Bilimleri Fakültesi, Makine Mühendisliği \\ Bölümü, 60150, Tokat. \\ ${ }^{2}$ Tokat Gaziosmanpaşa Üniversitesi, Fen Bilimleri Enstitüsü, Mekatronik Mühendisliği Bölümü, 60150, \\ Tokat. \\ Geliş Tarihi (Recived Date): 03.04.2018 \\ Kabul Tarihi (Accepted Date): 15.11.2018
}

\section{Özet}

Bu çalışmada, Ti6Al4V titanyum alaşımı levhalar Nd:YAG lazer kaynak yöntemiyle birleştirilmiştir. Lazer kaynaklı birleştirmelere kaynak öncesi ve sonrası ısıl işlem uygulanmıştır. Ön ısitma uygulanan lazer kaynaklı numunelere, kaynak sonrast gerilim giderme, solüsyon ısıl işlemi ve yaşlandırma ısıl işlemi uygulanmıştır. Isıl işlem şartlarının, lazer kaynaklı birleştirmelerin mikroyapı ve mekanik özelliklerine etkileri incelenmiştir. Deney sonuçları incelendiğinde, yaşlandırma isıl işlemi uygulanan numunelerin mikroyapısı yaşlandırma uygulanmayan numunelere göre daha kaba taneli bir yapıdan oluşum gösterdiği gözlenmiştir. Yaşlandırma uygulanan numunelerde süneklik ve tokluk değerlerinde artış gözlenirken yaşlandırma uygulanmayan numunelerin sertlik ve çekme dayanımlarında artış tespit edilmiştir.

Anahtar kelimeler: Titanyum alaşımı, lazer kaynak, ısıl işlem, mikroyapı, mekanik özellikler.

\section{Effects of heat treatments on the microstructure and mechanical properties of Nd:YAG laser beam welded Ti6Al4V alloy}

\begin{abstract}
In the present study, Ti6Al4V titanium alloy plates were joined using Nd:YAG laser beam welding method. Pre-and post-weld heat treatments were applied to laser welded

\footnotetext{
* Ceyhun KÖSE, ceyhun.kose@gop.edu.tr, https://orcid.org/0000-0002-3907-2226

Engin KARACA, engin.karaca@gop.edu.tr, https://orcid.org/0000-0003-0446-8463
} 
joints. After welding stress relieving, solution heat treatment and ageing were also applied to preheated laser welded samples. Effects of heat treatment conditions on microstructure and mechanical properties of laser beam welded joints were studied. The results showed that the aged samples were found to be made of coarsened grains compared to microstructures of non-aged samples. There were increases in ductility and toughness of samples applied to ageing increased, while hardness and tensile strength of non-aged samples were higher.

Keywords: Titanium alloy, laser welding, heat treatment, microstructure, mechanical properties.

\section{Giriş}

Titanyum alaşımları, $\alpha$ (alfa), $\alpha+\beta$ alaşımları ve $\beta$ (beta) alaşımları olmak üzere başlıca üç grupta sınıflandırılabilir. $\alpha$ alaşımlarının tüm yapısını $\alpha$ fazı oluştururken, $\beta$ alaşımlarının yapısında büyük ölçüde $\beta$ fazı bulunmaktadır ve bu yapıya çözündürme sıcaklığından itibaren soğutarak ulaşılabilmektedir. $\alpha+\beta$ alaşımları ise oda sıcaklığında hem $\alpha$ hem de $\beta$ fazını içermektedir [1]. $\alpha+\beta$ alaşımları içinde en çok Ti6Al4V kullanılmaktadır. Düşüuk yoğunluk, ısıl direnci, yüksek mekaniksel dayanım, korozyon dayanımı, biyouyumluluk özellikleri nedeniyle Ti6Al4V alaşımı çok geniş bir kullanım alanına sahiptir [2,3]. Bu dayanıklı ve hafif alaşımlar, jet motorları, uzay araçları, füze, basınç kazanı, ortodonti, medikal implant ve cerrahi aletlerin yapımı gibi pek çok uygulamalarda kullanılmaktadır $[4,5]$.

Ti6Al4V alaşımı, TIG, sürtünme, sürtünme-karıştırma, plazma ark, elektron 1şın, lazer kaynağı gibi pek çok yöntemle birleştirebilmektedir [2,5,6]. Lazer kaynak yöntemi düşük 1S1 girdisi, yüksek yoğunlaşma enerjisi, yüksek kaynak ilerleme hızı, dar kaynak bölgesi, derin nüfuziyetli birleştirmeler elde edilebilmesi, yüksek mekanik dayanım, düşük distorsiyon ve ilave metal kullanmadan kaynak yapabilme imkanından dolayı geleneksel kaynak yöntemlerinden ayrılır [7-14]. Fiber optik kablo destekli lazer kaynak sistemleri ise; düşük 1şın sapma oranı, fileksibl (esnek) 1şın dağıtımı, düşük bakım maliyeti, yüksek verimlilik ve yüksek kaliteli kaynaklı birleştirmeler sunmaktadır [15].

Titanyum ve alaşımlarının kaynağında yüksek ısı girdisine bağlı yavaş soğuma, kaynak dikişinde tane irileşmesine neden olmaktadır. Titanyum ve alaşımlarının kaynağında, kaynak bölgesine iletilen ısı girdisi azaltılarak soğuma hızının arttırılması ve dar bir kaynak dikiş biçimi elde edilmesi önerilmektedir. Ti6Al4V titanyum alaşımlarının elektron 1şın ve lazer 1şın kaynaklı birleştirmelerinde düşük 1sı girdisine bağlı hızlı soğumadan dolayı kaynak dikişinde ince taneli birincil $\beta$ oluşum göstermekte ve bu mikroyapısal dönüşüm de dayanım artışına neden olmaktadır [6]. Ancak, kaynak dikişinin hızlı soğuması durumunda baskın bir şekilde martenzitik yapı oluşmaktadır [16]. Martenzitik yapı, ana malzemeye kıyasla kaynak dikişinin tokluğunu düşmesine sebebiyet vermektedir [16,17]. Kaynak metali ve ITAB'daki süneklik kayıpları, kaynak sonrası uygulanan ısıl işlemler ile yeniden düzenlenerek iyileştirilebilmektedir [17]. Düşük sünekliğe sahip $\alpha+\beta$ titanyum alaşımlarının kaynak sonrası 1sıl işlemi, $\beta$ geçiş sıcaklığının altında yapılması önerilmektedir [18]. Titanyum ve alaşımlarının kaynaklı birleştirmelerine uygulanan gerilim giderme tavı, dayanım ve süneklik üzerine olumsuz bir etki oluşturmamaktadır. Gerilim giderme tavlaması ile birlikte, kaynak dikişinin soğuması esnasında oluşabilecek iç gerilmeler mümkün mertebe azaltılabilmektedir. 
Titanyum ve alaşımlarının kaynaklı birleștirmelerine kaynak sonrası uygulanan solüsyona alma, yaşlandırma gibi ısıl işlemler ise; kaynaklı birleştirmenin kırılma tokluğunu, sünekliğini, korozyon direncini ve yüksek sıcaklıklara dayanımı arttırmaktadır.

Literatürde Ti6Al4V titanyum alaşımının elektron 1şın kaynağı, ilave metal kullanımlı ve ilave metal kullanımsız lazer kaynağı, TIG (Tungsten Inert Gas) kaynak yöntemi ile birleştirmelerine ait çalışmalar bulunmasına rağmen [2,4,5,15,17,18], Robotik Nd:YAG lazer kaynaklı birleştirmelere kaynak öncesi ve sonrası uygulanan isıl işlemlerin etkilerini inceleyen çalışma yeterince bulunmamaktadır. Bu çalışmada Ti6Al4V levhalar, fiber optik 1şın dağıtım sistemi destekli Nd:YAG lazer kaynak yöntemiyle birleştirilmiştir. Kaynak öncesi ön tavlama gerçekleştirilmiş, kaynak sonrası ise iki farklı ısıl işlem prosedürü uygulanmıştır. Isıl işlemlerin, lazer kaynaklı Ti6Al4V alaşımının mikroyapı ve mekanik özelliklerine etkileri incelenmiştir.

\section{Deneysel çalışmalar}

\subsection{Malzeme, kaynak işlemi ve isıl işlem prosedürü}

Bu çalışmada, endüstrinin birçok alanında tercih edilen, kimyasal bileşimi Tablo 1'de verilen Ti6A14V alaşımı kullanılmıştır.

Tablo 1. Ti6Al4V alaşımının kimyasal kompozisyonu.

\begin{tabular}{cccccccc}
\hline$\% \mathrm{C}$ & $\mathrm{Al}$ & $\mathrm{V}$ & $\mathrm{Fe}$ & $\mathrm{N}$ & $\mathrm{O}$ & $\mathrm{H}$ & $\mathrm{Ti}$ \\
\hline 0.010 & 6.02 & 4.14 & 0.098 & 0.007 & 0.12 & 0.002 & Kalan \\
\hline
\end{tabular}

Deney malzemesi, 100x330x4mm ölçülerinde kaynak işlemine hazır duruma getirilmiştir. Deney numuneleri Tablo 2'de belirtilen parametrelerle, $4 \mathrm{~kW}$ gücüne sahip Nd:YAG lazerin, FANUC ROBOT R-2000 iB 210F marka robota entegre edilmesiyle oluşturulan kaynak tertibatıyla (lazer, fiber optik kablo vasıtasıyla lazer kaynak kafasına iletilmektedir), yatay pozisyonda ve ilave metal kullanılmadan birleştirilmiştir. Kaynak öncesi ve sonrası Tablo 3' de belirtilen parametrelerde 1sıl işlemler uygulanmıştır.

Tablo 2. Lazer kaynak parametreleri.

\begin{tabular}{ccccccc}
\hline Numuneler & $\begin{array}{c}\text { Lazer } \\
\text { gücü } \\
(\mathrm{W})\end{array}$ & $\begin{array}{c}\text { Kaynak } \\
\text { h1z1 } \\
(\mathrm{mm} / \mathrm{s})\end{array}$ & $\begin{array}{c}\text { Koruyucu } \\
\text { gaz }\end{array}$ & $\begin{array}{c}\text { Gaz } \\
\text { basınc1 } \\
\text { (bar })\end{array}$ & $\begin{array}{c}\text { Odak } \\
\text { mesafesi } \\
(\mathrm{mm})\end{array}$ & $\begin{array}{c}\text { Is1 girdisi } \\
(\mathrm{kJ} / \mathrm{mm})\end{array}$ \\
\hline $\mathrm{A} 1$ & 1500 & 9 & $\mathrm{He}$ & 1 & 190 & 0.16 \\
\hline $\mathrm{B} 1$ & 2000 & 9 & $\mathrm{He}$ & 1 & 190 & 0.22 \\
\hline
\end{tabular}

Tablo 3. Isıl işlem prosedürü.

\begin{tabular}{|c|c|}
\hline Numuneler & Isıl işlem şartları \\
\hline A1 & \multirow{2}{*}{$\begin{array}{c}350^{\circ} \mathrm{C} / 20 \text { dak ön tav }+720^{\circ} \mathrm{C} / 1 \text { saat gerilim giderme/havada soğutma }+ \\
920^{\circ} \mathrm{C} / 1 \text { saat solüsyona alma/havada soğutma }+650^{\circ} \mathrm{C} / 2 \text { saat } \\
\text { yaşlandırma/havada soğutma }\end{array}$} \\
\hline $\begin{array}{c}\text { Ana } \\
\text { malzeme (A) }\end{array}$ & \\
\hline $\mathrm{B} 1$ & \multirow{2}{*}{$\begin{array}{c}350^{\circ} \mathrm{C} / 20 \text { dak ön tav }+720^{\circ} \mathrm{C} / 1 \text { saat gerilim giderme/havada soğutma }+ \\
920^{\circ} \mathrm{C} / 1 \text { saat solüsyona alma/havada soğutma }\end{array}$} \\
\hline $\begin{array}{c}\text { Ana } \\
\text { malzeme (B) }\end{array}$ & \\
\hline
\end{tabular}




\subsection{Mekanik testler ve mikroyapı analizleri}

Birleştirmelerin mekanik özelliklerini belirleyebilmek için her bir parametre için 4'er adet çekme testi numuneleri ISO 4136: 2012, çentik darbe testi numuneleri ISO 9016: 2012 standartlarında hazırlanmıştır. Çekme testi INSTRON marka $100 \mathrm{kN}$ kapasiteli çekme test cihazında $10 \mathrm{~mm} /$ dak ilerleme hızında, darbe çentik testi ise oda sıcaklığında OHR\&FEDERAF AG PSW 13/15 marka deney cihazıyla gerçekleştirilmiştir. MicroVickers sertlik ölçümü ise, GALILEO marka ölçüm cihazında uca 15 saniye $200 \mathrm{~g}$ yük uygulanarak belirlenmiştir.

Isıl işlem uygulanmış numunelerin mikroyapı değişimlerini karakterize etmek için Kroll's solüsyonu ile dağlama işlemi prosedürü uygulanmıştır. Mikroyapı incelemeleri 5x-100x büyütmeli NIKON marka optik mikroskop, JEOL JSM 6060 LV ve JEOL JSM 7001 LV marka taramalı elektron mikroskobu (SEM) ve OXFORD X-MAX 80 (EDS) donanımı ile gerçekleştirilmiştir.

\section{Sonuçlar ve tartışma}

\subsection{Mikroyapt incelemeleri}

Ana malzeme (A ve B numuneleri) mikroyapılarının eş eksenli $\alpha$ tanelerinden ve tane sınırlarındaki $\beta$ tanelerinden meydana geldiği görülmektedir (Şekil 1).
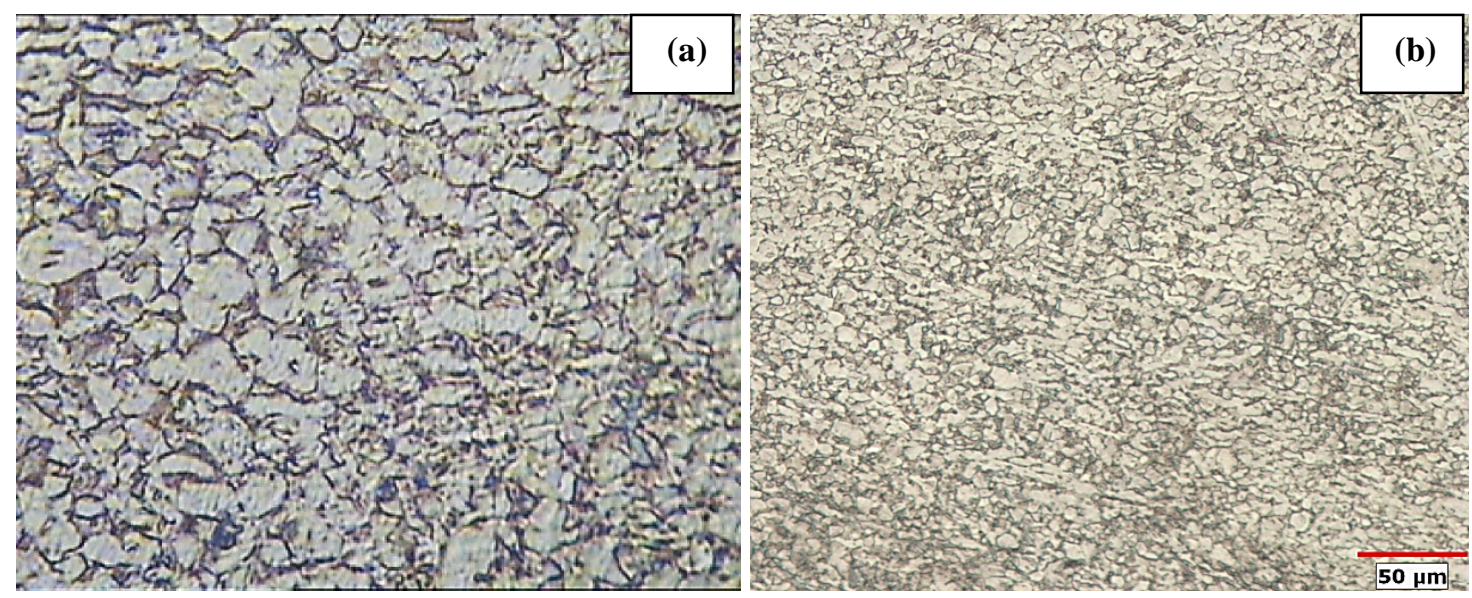

Şekil 1. Ana malzemeler; (a) gerilim giderme + solüsyona alma + yaşlandırma uygulanan A numunesi (1000x), (b) gerilim giderme + solüsyona alma 1sıl işlemi uygulanan B numunesi (200x).

Kaynak sonrası tavlama işlemi süreciyle, malzemede termodinamik denge elde edilmesi amaçlanmaktadır. Lazer kaynağı veya elektron 1şın kaynağıyla birleştirilen $\alpha+\beta$ titanyum alaşımlarının ısıl işlemler sonrası mikroyapıları; martenzit fazı içerisinde $\beta$ fazı oluşumu göstermekte ya da $\alpha$ fazı çökeltileri kalıntı biçiminde mikroyapı içerisinde yer almaktadır. Isıl işlem süresi ya da 1sıl işlem sıcaklık derecesi arttıkça, aşırı yaşlanma etkisiyle tane büyümesi oluşumları meydana gelmektedir [16]. Şekil 2'de, yaşlandırma 1sıl işlemi uygulanmış kaynaklı birleştirmenin (A1 numunesi) taneyapısının, yaşlandırma uygulanmayan ana malzeme ve lazer kaynaklı mikroyapısına göre (B ve B1 numunesi) daha fazla irileştiği açık bir şekilde görülmektedir. Kaynak sonrası uygulanan isıl işlemler sonrası elde edilen bu mikroyapı değişimi, kaynaklı 
birleştirmenin çekme dayanımında bir miktar azalmaya neden olması beklenirken, kaynak bölgesinin sünekliğinde ise artış beklenmektedir.

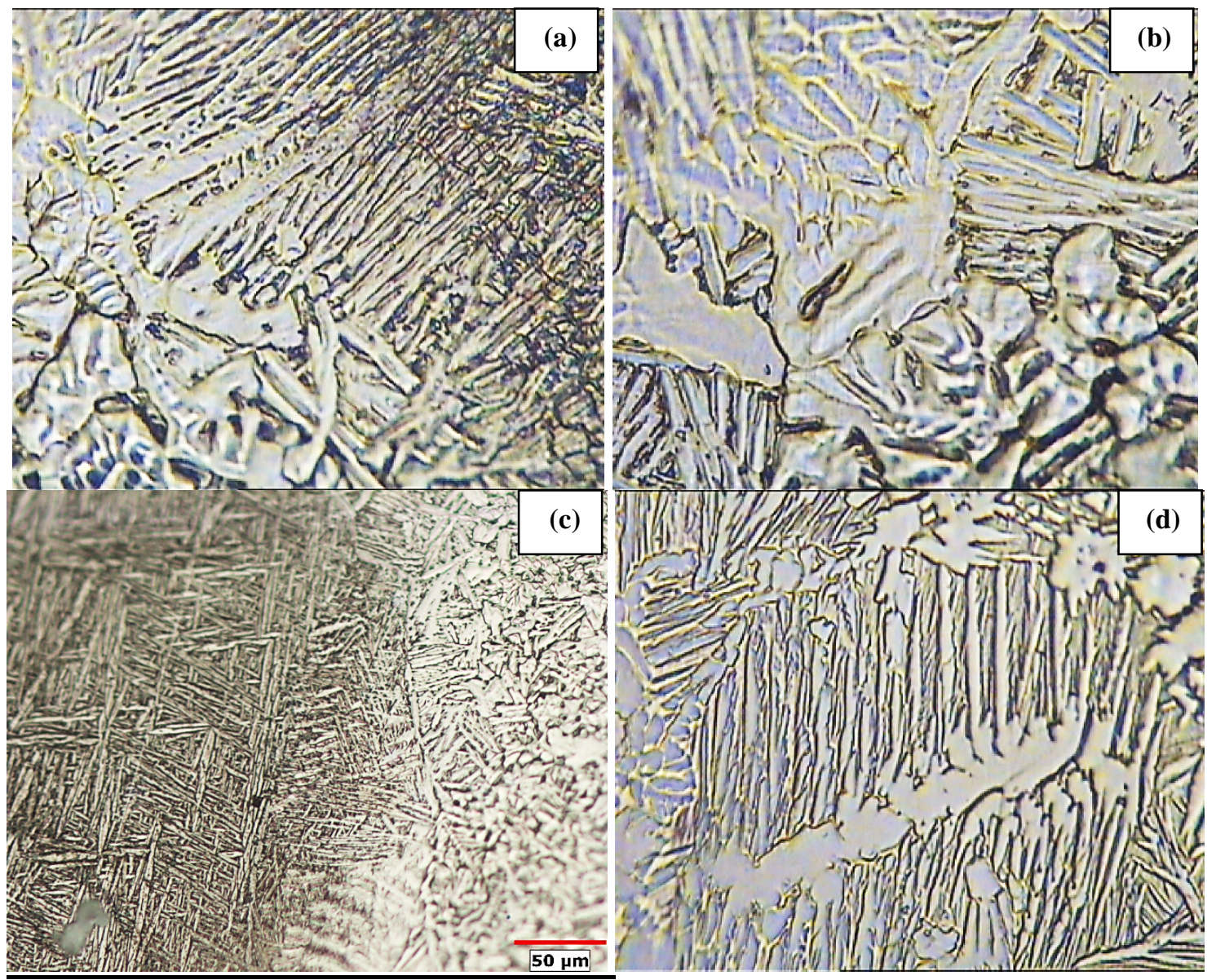

Şekil 2. Isıl işlem uygulanmış lazer kaynaklı numunelerin mikroyapı görüntüleri; a-) A1 numunesine ait ITAB (1000x) ve b-) kaynak metali görüntüsü (1000x), c-) B1 numunesine ITAB (200x) ve d-) Kaynak metali görüntüsü (1000x).

Lazer kaynaklı birleştirmelerde dar bir ITAB oluşumu meydana geldiği optik mikroskop görüntülerinden anlaşılmaktadır (Şekil 2). Yaşlandırma 1sıl işlemi uygulanan ve uygulanmayan lazer kaynaklı numunelerin özellikle kaynak metali mikroyapısında yüksek sıcaklığın ve bekleme süresinin etkisiyle belirgin tane büyümesi, lamellar $\alpha+\beta$ faz yapısı ve $\alpha$ fazı tane sınırlarında basket-weave Widmanstatten tane yapısı oluşumu meydana geldiği görülmektedir. Tane irileşmesi, beklenildiği gibi yaşlandırma uygulanan numunelerde daha etkili gerçekleşmiştir. Isıl işlem sıcaklık değerleri, $\beta$ geçiş sicaklığının altında olması nedeniyle $\alpha$ tane sınırı yapısının tamamen $\beta$ fazına dönüşmesi beklenmeyen bir durumdur. Yaşlandırma süresine ve soğutma şartlarına bağlı olarak $\alpha$ tane sınırı yapısıyla birlikte $\alpha$ plakaları, tane sınırında dönüşmüş $\beta$ taneleri bulunabilir [6,19]. Yaşlandırma ısıl işlemi uygulanmış numunede, dönüşmüş $\beta$ hacim oranının artış gösterdiği mikroyapı görüntülerinden açık bir şekilde görülebilmektedir. Ayrıca, B1 numunesinin kaynak metalinde porozite oluşumu gözlenmiştir (Şekil 3). Lazer kaynaklı titanyum alaşımlarında gözenek oluşumuyla genellikle karşılaşılmaktadır. Gaz tipi poroziteler özellikle, kaynak dikişinin katılaşması esnasında, kaynak havuzundaki hidrojenin uzaklaştırılamaması nedeniyle oluşum 
göstermektedir [20]. Gözenek oluşumu nedeniyle, kaynaklı birleştirmelerin mekanik dayanımında düşüşlerin yaşanması muhtemeldir.

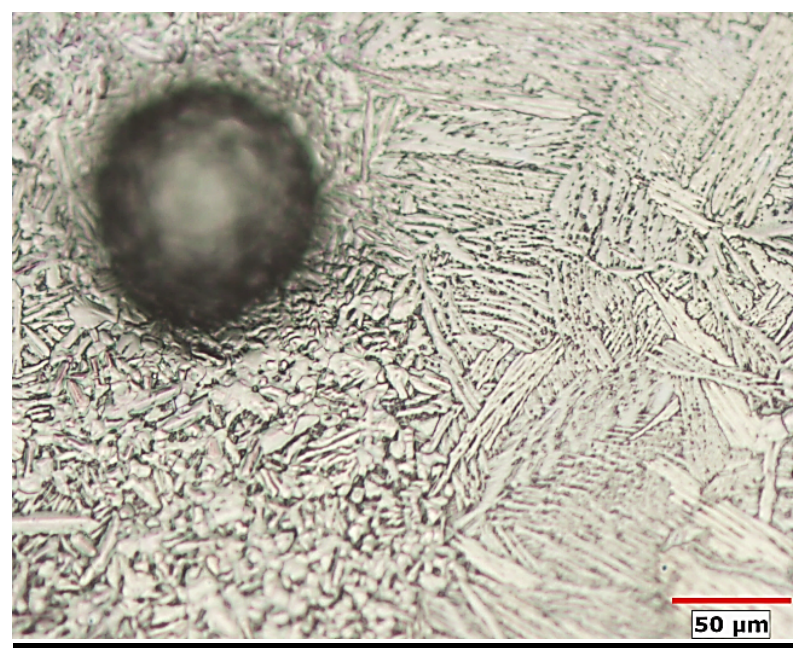

Şekil 3. B1 numunesinin kaynak metalinde gözenek oluşumu (200x).

Tüm ısıl işlem şartları ve kaynak parametreleri için gerçekleştirilen EDS analizleri sonuçları incelendiğinde, ana metal, ITAB ve kaynak metali bölgelerinden önemli derecede element kayıplarının yaşanmadığı tespit edilmiştir (Şekil 4). Bu sonuçlardan, 1S1 girdisinin veya ısıl işlemlerin lazer kaynaklı birleştirmeler üzerinde element kaybı oluşturmadığı açık bir şekilde söylenebilir.
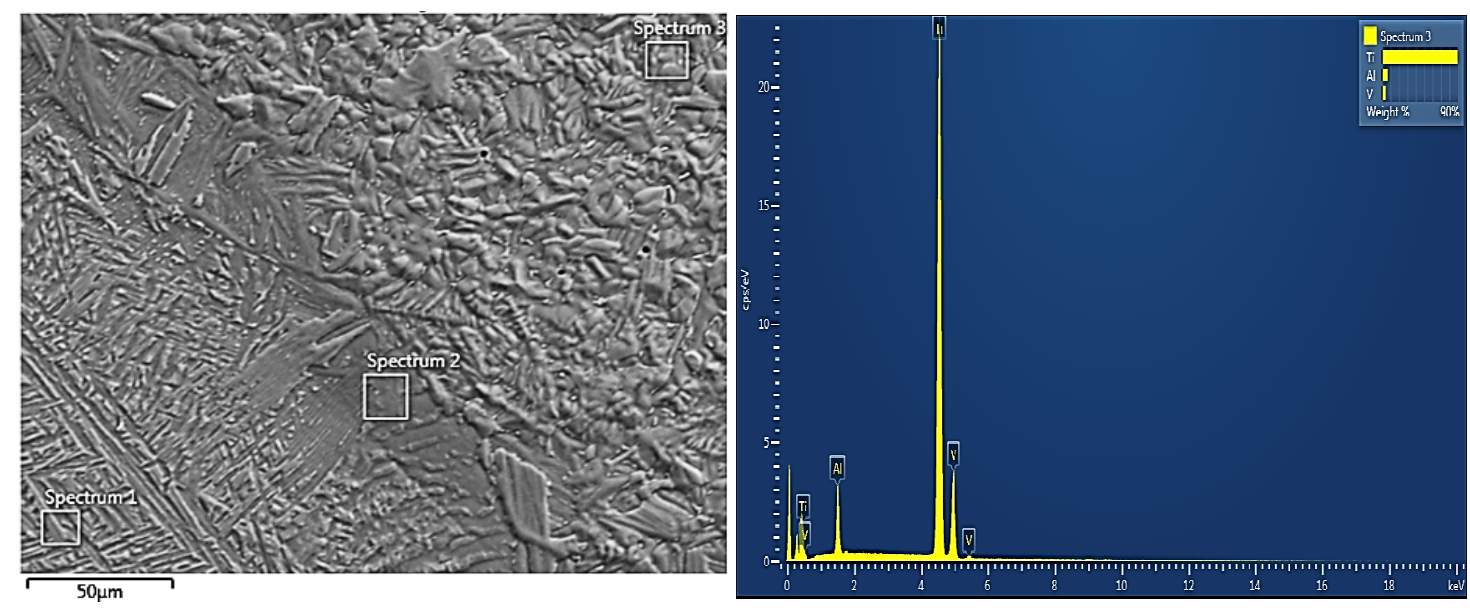

Şekil 4. A1 numunesine ait EDS analizi.

\section{2. Çekme deneyi}

Isıl işlemler uygulanmış ana malzeme ve lazer kaynaklı numunelerin mekanik özelliklerini belirlemek için çekme testi uygulanmış ve sonuçlar Tablo 4'de gösterilmiştir. 
Tablo 4. Isıl işlem uygulanan ana malzeme ve lazer kaynaklı deney numunelerinin çekme deneyi sonuçları.

\begin{tabular}{cccc}
\hline Numuneler & $\begin{array}{c}\text { Çekme dayanımı } \\
(\mathrm{MPa})\end{array}$ & $\begin{array}{c}\text { Akma dayanımı } \\
(\mathrm{MPa})\end{array}$ & Uzama (\%) \\
\hline $\mathrm{A}$ & 1025 & 944 & 20 \\
\hline $\mathrm{B}$ & 1039 & 955 & 18 \\
\hline $\mathrm{A} 1$ & 791 & 730 & 12 \\
\hline $\mathrm{B} 1$ & 840 & 785 & 10.5 \\
\hline
\end{tabular}

Çekme deneyi sonuçları incelendiğinde, 1sıl işlemlerin etkisiyle meydana gelen mikroyapısal dönüşümler sonucu, yaşlandırma uygulanmayan ana malzemenin (B numunesi) çekme dayanımı, yaşlandırma uygulanan ana malzemenin (A numunesi) çekme dayanımından yüksek bulunmuştur. Ancak, yüzde uzama az da olsa B numunesinde daha düşük bulunmuştur. Lazer kaynaklı B1 numunesinin çekme dayanımı ise, A1 numunesinin çekme dayanımından daha yüksek olduğu tespit edilmiştir. Yaşlandırma 1sıl işlemi uygulanan A1 numunesinin çekme dayanımının düşük, sünekliğinin yüksek çıkmasının ana nedeni, ısıl işlemler sonrası $\alpha$ tanelerinin daha iri boyutlarda oluşum göstermesi ve temperlenmiş martenzitin varlığından kaynaklandığı düşünülmektedir. Tüm ısıl işlem şartlarında kaynaklı birleştirmelerin çekme dayanımları ana malzemelerden daha düşük bulunmuştur. Çekme deneyi sonrasında kopmalar ITAB ve kaynak metalinden gerçekleşmiştir. Bunun nedenleri arasında, kaynak dikişinde meydana gelen poroziteler, kaynak dikişinde çöküntü (underfills), mikroçatlaklar ve mikroyapısal dönüşümler sayılabilir. Lazer kaynaklı birleştirmelerin mikroyapılarında ince $\beta$ tanelerinin oluşum göstermesi nedeniyle yüksek süneklik göstermesi [21] beklenebilirdi. Bu çalışmada, kaynak dikişi mikroyapısında $\alpha$ plateletlerin (levhacıkların) kabalaşmasına rağmen, lamellar yapı oluşumu, çekme dayanımında ve süneklikteki azalmaya neden olarak düşünülmektedir. Araştırmacılar, kaynak sonrası ısıl işlemler ile birlikte, kaynak metali mikroyapısında lameller yapının stabil kalması nedeniyle, kaynaklı birleştirmede ana metale göre daha düşük süneklik değerleri elde edileceğine işaret etmektedir [18]. Aynı zamanda, kaynak sonrası uygulanan yaşlandırma 1sıl işlemi ile birlikte martenzit ve Widmanstatten $\alpha$ yapısının lamellar $\alpha-\beta$ tane yapısına dönüşmesiyle, akma ve çekme dayanımında azalmaların, süneklikte ise artış meydana geleceği araştırmacılar tarafından bildirilmektedir [6,16,17]. Artan sıcaklıklarda, düzensiz şekilli $\beta$ tanelerinin oluşum göstermesi nedeniyle, ana malzemeye kıyasla, kaynaklı birleştirmelerin darbe/kırılma tokluğu ve akma dayanımında azalmaların yaşanacağı araştırmacılar tarafından vurgulanmaktadır [22]. Kaynak dikişinin katılaşması esnasında oluşabilecek mikrosegregasyonlar da sünekliği azaltan etmenler arasında sayılabilir. Genel olarak çekme deneyi sonuçları incelendiğinde, iki farklı ısıl işlem prosedürü uygulanan lazer kaynaklı numunelerin çekme dayanımları arasında çok büyük farklılıkların yaşanmadığı sonucuna varılmıştır. Bu sonucun alınmasının ana nedeni, 1sıl işlem şartlarının $\beta$ geçiş sıcaklığının altında gerçekleştirilmesi ve böylelikle de birincil $\beta$ tane boyutlarında önemli değişimlerin meydana gelmemesinden ileri geldiği düşünülmektedir.

Çekme deneyi sonrası ana malzemeler ve lazer kaynaklı B1 numunelerinin kırılma yüzeylerine ait SEM görüntüleri incelendiğinde, gözeneklerden anlaşılacağı üzere, ısıl işlemli titanyuma ait tipik kırılma biçimi olan sünek kırılma biçiminde kırılmaların gerçekleştiği açık bir şekilde görülebilmektedir (Şekil 5). Kaynaklı birleştirmelerin kırılma yüzeyi görüntülerinde herhangi bir inklüzyon oluşumu gözlenmemiştir. 


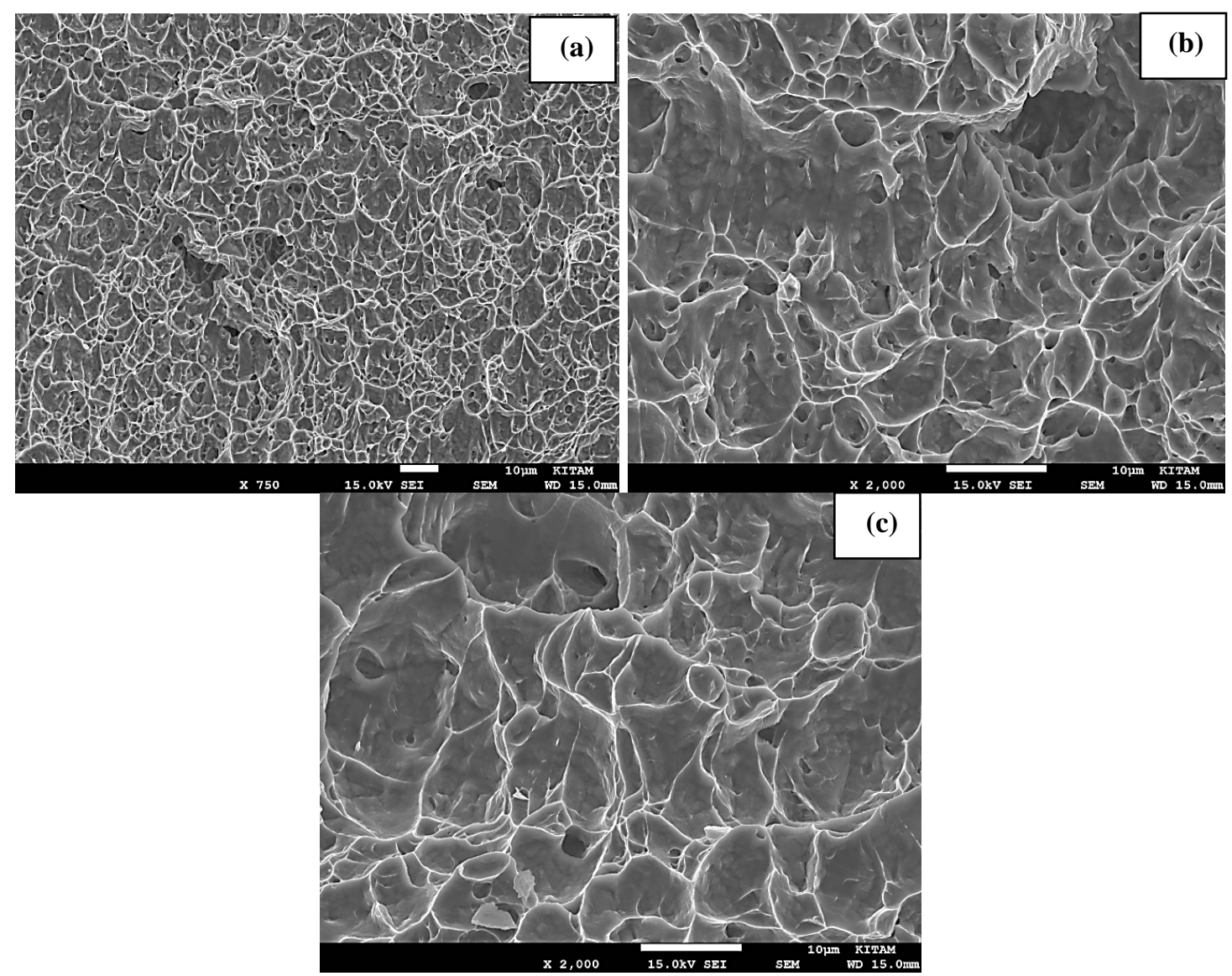

Şekil 5. Çekme deneyi sonrası kırılma yüzeyi SEM görüntüleri; a-) A ve b-) B numunesi, c-) B1 numunesi.

\section{3. Çentik darbe testi}

Isıl işlemli ana malzeme ve lazer kaynaklı numunelerin oda sıcaklığında darbe toklukları belirlenmiş ve sonuçlar Şekilde 6' da verilmiştir.

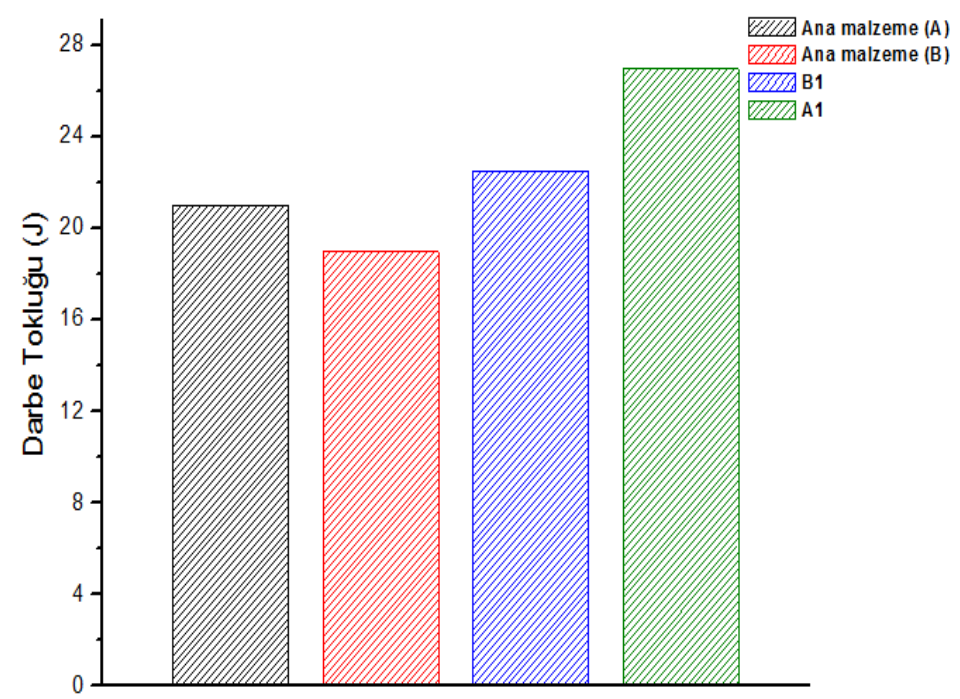

Şekil 6. Çentik darbe deneyi sonuçları 
Yaşlandırma 1sıl işlemi uygulanan A numaralı ana malzemenin darbe tokluğu, yaşlandırma uygulanmayan B numaralı ana malzemeye kıyasla daha yüksek bulunmuştur (21J ve 19J). Ana malzemelerin darbe toklukları, kaynaklı birleștirmelerin darbe tokluğundan daha düşük bulunmuştur (Şekil 6). Kaynak sonrası uygulanan isıl işlemlerin etkisiyle, kaynak dikişi mikroyapısındaki taneiçi $\alpha$ tanelerinin hacim oranı artış göstererek darbe tokluğunu arttıracağı araştırmacılar tarafından vurgulanmaktadır $[17,23]$, ayrıca martenzitin $\alpha+\beta$ faz yapısına dönüşmesiyle süneklikteki artışla birlikte darbe tokluğunda iyileşmelerin meydana geldiği düşünülmektedir. Kaynak sonrası 1sıl işlemlerle, $\alpha$ tane sınırının kabalaşmasıyla, tane sınırındaki çatlak ilerleyişinin yönü değişerek darbe tokluğunda iyileşmeler yaşanacağı da araştırmacılar tarafından özellikle bildirilmektedir [17,23]. Benzer çalışmalar gerçekleştiren araştırmacılar ayrıca, titanyum alaşımlarının darbe tokluğunu arttırmak için, düşük kaynak hızı veya yüksek lazer gücü kullanılarak, 1sı girdisinin arttırılmasıyla birlikte martenzit yapısının asiküler $\alpha$ (iğnemsi) veya Widmanstatten $\alpha$ tane yapısına dönüştürülmesi gerektiğini vurgulamaktadır [24].

Çentik darbe deneyi sonrası ana malzemeler ve lazer kaynaklı A1 numunelerinin kırılma yüzeyi morfolojisi SEM ile incelenmiştir (Şekil 7). Ana malzemelere ait kırılma yüzeyi SEM görüntüsünden kırılmanın sünek şekilde gerçekleştiği açık bir şekilde anlaşılmaktadır. Lazer kaynaklı numunenin ise tanelerarası kırılma ile birlikte klivaj kırılma biçiminde kırılmaların gerçekleştiği kırılma yüzeyi morfolojilerinden anlaşılmaktadır.

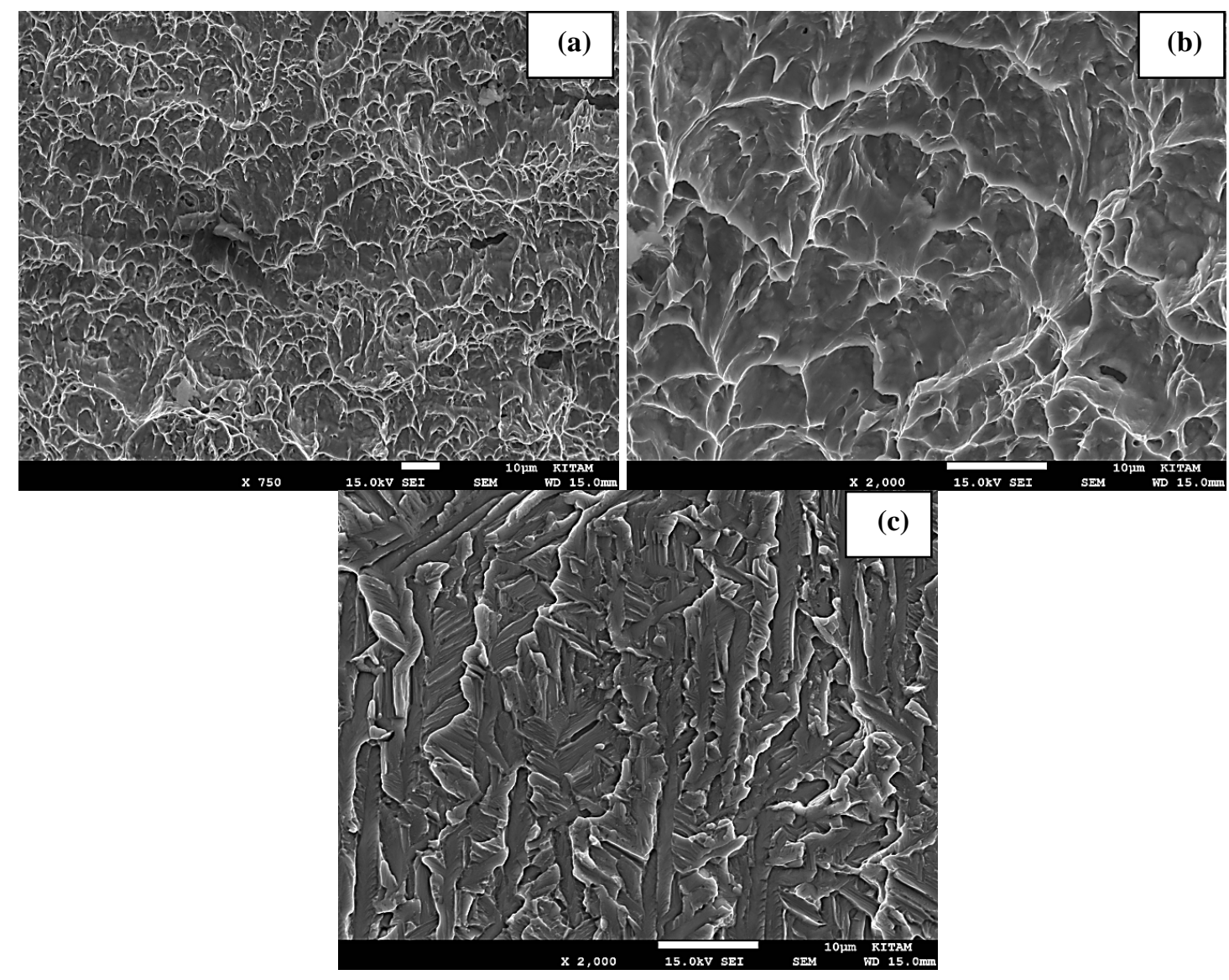

Şekil 7. Çentik darbe deneyi sonrası kırılma yüzeyi SEM görüntüleri; a-) A ve b-) B numunesi, c-) A1 numunesi. 


\subsection{Mikrosertlik testi}

Lazer kaynağı, geleneksel kaynak yöntemlerine göre yüksek güç yoğunluğuna sahip olması nedeniyle, düşük 1sı girdisi ve hızlı katılaşma oluşturmakta ve kaynaklı birleştirmelerde yüksek sertlik değerleri elde edilmektedir. Isıl işlem uygulanmış lazer kaynaklı numunelerin sertlik değerleri incelendiğinde (Şekil 8), kaynak metali ve ITAB sertliğinin ana metalden daha yüksek değerlerde olduğu tespit edilmiştir.

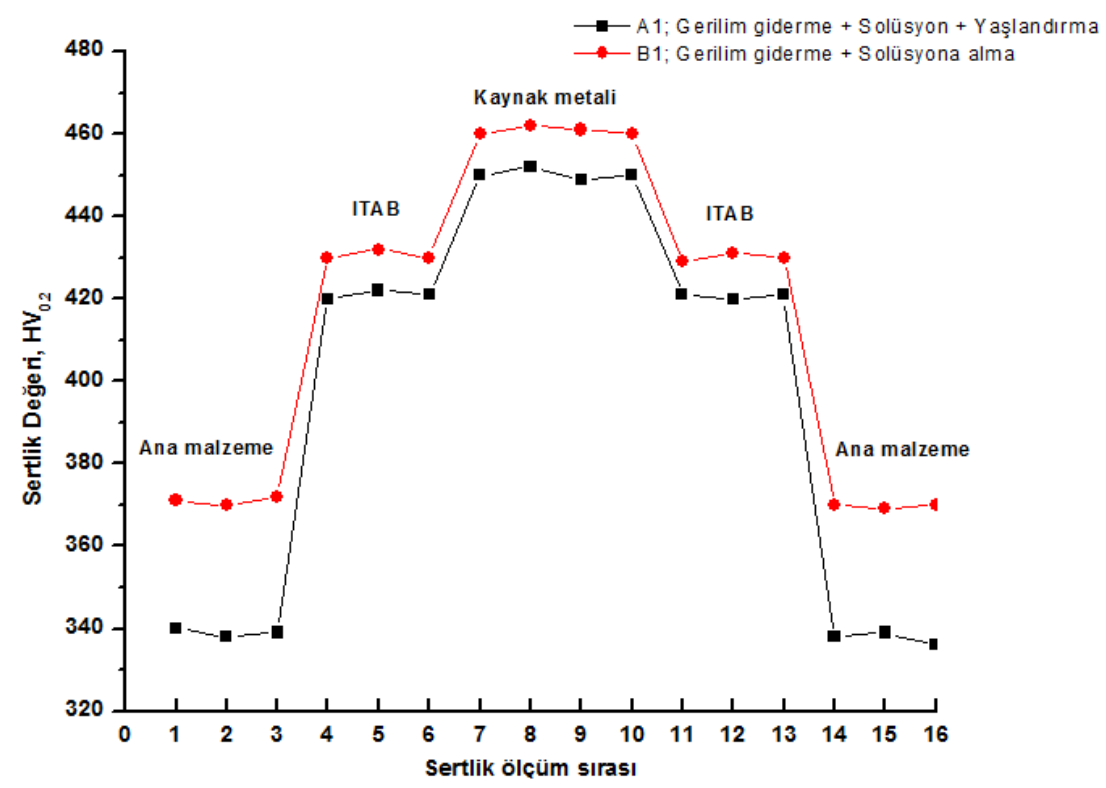

Şekil 8. Lazer kaynaklı birleştirmelerin sertlik dağılımları.

En sert bölge olarak, kaynak metali olarak bulunmuştur. Kaynak metalinin, ITAB'a göre daha sert bulunmasının ana nedeni, bu bölgenin daha ince yapılı tanelerden oluşum göstermesidir. Kaynak sonrası ısıl işlemler ile, martenzitin $\alpha+\beta$ faz yapısına dönüşmesi ve $\alpha$ fazı levhacıklarının kalıntı $\beta$ fazından dönüşümüyle birlikte, ana metale kıyasla ITAB ve kaynak metalinde sertlik artışı görüleceği vurgulanmaktadır [8]. $\beta$ fazı $\alpha$ fazına göre daha yumuşak ve sünektir, kaynak sonrası 1sıl işlemlerle birlikte $\beta$ faz yapısının azalması sonucu özellikle kaynak metalinde sertlik artışı gerçekleşeceği araştırmacılar tarafından bildirilmektedir [6]. Yaşlandırma ısıl işlemi uygulanan lazer kaynaklı numunenin yaşlandırma uygulanmamış numunenin sertliğinden bir miktar düşük bulunmuştur. Yüksek sıcaklıklarda $\alpha$ martenzit fazının, $\beta$ yapısına dönüşümüyle ve tane yapısının daha da kabalaşmasıyla sertlik düşüşleri yaşanmaktadır. Kaynak sonrası isıl işlem sıcaklığı arttıkça da sertlikte düşüş meydana geleceğine özellikle dikkat çekilmektedir [19].

\section{Sonuçlar}

1- Yaşlandırma 1sıl işlemi uygulanan ve uygulanmayan lazer kaynaklı numunelerin özellikle kaynak metali mikroyapısında yüksek sıcaklığın ve bekleme süresinin etkisiyle belirgin tane büyümesi, lamellar $\alpha+\beta$ faz yapısı ve $\alpha$ fazı tane sinırlarında basket-weave Widmanstatten tane yapısı oluşumu meydana gelmiştir. Tane irileşmesi, beklenildiği gibi yaşlandırma uygulanan numunede daha etkili gerçekleşmiştir. 
2- Kaynaklı birleștirmelerin çekme dayanımları ana malzemelerden daha düşük bulunmuştur. Bunun nedenleri arasında, kaynak dikişinde meydana gelen poroziteler, dikişte çöküntüler, mikroçatlaklar ve mikroyapısal dönüşümler sayılabilir. Lazer kaynaklı numunelerin çekme dayanımları arasında çok büyük farklılıkların yaşanmadığı sonucuna varılmıștır. Bu sonucun alınmasının ana nedeni, ısıl işlem şartlarının $\beta$ geçiş sıcaklığının altında gerçekleştirilmesi ve böylelikle de birincil $\beta$ tane boyutlarında önemli değişimlerin meydana gelmemesinin neden olduğu düşünülmektedir.

3- Yaşlandırma uygulanan ana malzemenin (A numunesi) darbe tokluğu yaşlandırma uygulanmayan ana malzemeye (B numunesi) kıyasla darbe tokluğu daha yüksek bulunmuştur. Ana malzemelerin darbe toklukları, kaynaklı birleştirmelerin darbe tokluğundan daha düşük bulunmuştur. Kaynak sonrası uygulanan isıl işlemlerin etkisiyle, kaynak dikişi mikroyapısındaki taneiçi $\alpha$ tanelerinin hacim oranı artış göstererek darbe tokluğunu arttırdığı düşünülmektedir. Ayrıca, martenzitin $\alpha+\beta$ faz yapısına dönüşmesi süneklik artışına neden olarak darbe tokluğunu iyileştirici rol oynamıştır.

4- Sertlik incelemeleri sonucunda, kaynak metali ve ITAB sertliğinin ana metalden daha yüksek değerlerde olduğu belirlenmiştir. En sert bölge, kaynak metali olarak tespit edilmiştir. $\beta$ fazı, $\alpha$ fazına göre daha yumuşak ve sünek olduğu bilinmektedir, kaynak sonrası 1sıl işlemlerle birlikte $\beta$ faz yapısının azalması sonucu özellikle kaynak metalindeki sertlik artışına ana neden olarak görülmektedir.

\section{Kaynaklar}

[1] Karaca, E., Robotik Nd:YAG fiber lazer kaynağı ile birleştirilen Ti6Al4V alaşımının mekanik, mikroyapı ve ısıl işlem özelliklerinin incelenmesi, Yüksek Lisans Tezi, Gaziosmanpaşa Üniversitesi, Fen Bilimleri Enstitüsü, Tokat, (2017).

[2] Karimzadeh, F., Heidarbeigy, M., ve Saatchi, A., Effect of heat treatment on corrosion behavior of Ti-6Al-4V alloy weldments, Journal of Materials Processing Technology A, 206, 1-3, 388-394, (2008).

[3] Yildız, A., Kaya, Y., ve Kahraman, N., Joint properties and microstructure of diffusion-bonded grade 2 titanium to AISI 430 ferritic stainless steel using pure Ni interlayer, The International Journal of Advanced Manufacturing Technology, 86, 5-8, 1287-1298, (2016).

[4] Akman, E., Demir, A., Canel, T., ve Sinmazçelik, T., Laser welding of Ti6Al4V titanium alloys, Journal of Materials Processing Technology, 209, 8, 37053713, (2009).

[5] Cao, X., ve Jahazi, M., Effect of welding speed on butt joint quality of Ti-6Al-4V alloy welded using a high-power Nd:YAG laser, Optics and Lasers in Engineering, 47, 11, 1231-1241, (2009).

[6] Kabir, A. S. H., Cao, X., Gholipour, J., Wanjara, P., Cuddy, J., Birur, A., ve Medraj M., Effect of postweld heat treatment on microstructure, hardness, and tensile properties of laser-welded Ti-6Al-4V, Metallurgical and Materials Transactions A, 4, 11, 4171, 4184, (2012).

[7] Köse, C., ve Kaçar, R., The effect of preheat \& post weld heat treatment on the laser weldability of AISI 420 martensitic stainless steel, Materiasl and Design, 64, 221-226, (2014).

[8] Köse, C., ve Kaçar, R., Mechanical properties of laser welded 2205 duplex stainless steel, Materials Testing, 54, 10, 779-785, (2014). 
[9] Köse, C., ve Kaçar, R., Effect of welding speed on the mechanical properties and microstructure of laser welded AISI 316L stainless steel, Journal of the Faculty of Engineering and Architecture of Gazi University, 30, 2, 225-235, 2015.

[10] Köse C., Kaçar R., Zorba A. P., Bağırova M., \& Allahverdiyev A. M. (2016). The effect of $\mathrm{CO}_{2}$ laser beamwelded AISI 316L austenitic stainless steel on the viability of fibroblast cells, in vitro. Materials Science and Engineering C, 60, 211-218.

[11] Köse, C., ve Kaçar, R., In vitro bioactivity and corrosion properties of laser beam welded medical grade AISI 316L stainless steel in simulated body fluid, International Journal of Electrochemical Science, 11, 2762-2777, (2016).

[12] Köse, C., An investigation of the surface characterization of laser surface remelted and laser beam welded AISI 316L stainless steel, International Journal of Electrochemical Science, 11, 3542-3554, (2016).

[13] Köse, C., Weldability of 5754 aluminum alloy using a pulsed Nd:YAG micro scale laser, Materials Testing, 58, 11-12, 963-969, (2016).

[14] Köse, C., Lazer ile yüzey modifikasyon uygulanan AISI 2205 paslanmaz çeliğin yüzey özelliklerinin incelenmesi, AKÜ Fen ve Mühendislik Bilimleri Dergisi, 16, 67-73, (2016).

[15] Quintino, L., Costa, A., Miranda, R., Yapp, D., Kumar, V., ve Kong, C. J., Welding with high power fiberlasers-A preliminary study, Materials and Design, 28, 4, 1231-1237, (2007).

[16] Murthy, K. K., ve Sundaresan, S., Phase transformations in a welded neartitanium alloy as a function of weld cooling rate and post-weld heat treatment conditions, Journal of Materials Science, 33, 3, 817-826, (1998).

[17] Thomas, G., Ramachandra, V., Ganeshan, R., ve Vasudevan, R., Effect of preand post-weld heat treatments on the mechanical properties of electron beam welded Ti-6Al-4V alloy, Journal of Materials Science, 28, 18, 4892-4899, (1993).

[18] Sundaresan, S., ve Ram, G.D.J., Use of magnetic arc oscillation for grain refinement of gas tungsten arc welds in $\alpha-\beta$ titanium alloys, Journal Science and Technology of Welding and Joining, 4, 3, 151-160, (1999).

[19] Babu, N.K., Raman, S.G., Sundara, M., Srinivasa, C.V., ve Reddy, G.M., Effect of beam oscillation on fatigue life of Ti-6Al-4V electron beam weldments, Materials Science and Engineering. A, 471, 1-2, 113-119, (2007).

[20] Kabir A. S. H., Cao X., Medraj M., Wanjara P., Cuddy J., ve Birur A., Effect of welding speed and defocusing distance on the quality of laser welded Ti-6Al-4V, In Proceedings of the Materials Science and Technology (MS\&T) Conference, Houston, TX, USA, 2787-2797, (2010).

[21] Tsay, L.W., ve Tsay C.Y., The effect of microstructures on the fatigue crack growth in Ti-6AI-4V laser welds, International Journal of Fatigue, 19, 10, 713$720,1997$.

[22] Wang, S.H., Wei, M.D., ve Tsay, L.W., Tensile properties of LBW welds in Ti6Al-4V alloy at evaluated temperatures below $450{ }^{\circ} \mathrm{C}$, Materials Letter, 57, 12, 1818-1823, (2003).

[23] Mohandas, T., Banerjee, D., ve Kutumba Rao, V.V., Microstructure and mechanical properties of friction welds of an $a+b$ titanium alloy, Materials Science and Engineering: A, 289, 1-2, 70-82, (2003).

[24] Barreda, J.L., Santamaria, F., Azpiroz, X., Irisarri, A.M., ve Varona, J.M., Electron beam welded high thickness Ti6Al4V plates using filler metal of similar and different composition to the base plate, Vacuum, 62, 2-3, 143-150, (2001). 